\title{
Chromium isotopes as a proxy for redox conditions on early Earth: Insights from Australian sedimentary rock records
}

\author{
JURAJ FARKAS ${ }^{1}$, ROBERT KLAEBE ${ }^{2}$, JESSICA \\ STROMBERG $^{3}$, SAM SPINKS ${ }^{3}$, GEREMIAH TOLEDO ${ }^{2}$, \\ SAVANNAH LIEBELT ${ }^{2}$, MORGAN BLADES ${ }^{2}$, ALAN \\ COLLINS $^{2}$ AND ROBERT FREI ${ }^{4}$
}

${ }^{1}$ University of Adelaide - Metal Isotope Group (MIG)

${ }^{2}$ University of Adelaide

${ }^{3}$ CSIRO - Mineral Resources

${ }^{4}$ University of Copenhagen

Presenting Author: juraj.farkas@adelaide.edu.au

Apart from being one of the most toxic and carcinogenic metal contaminants (i.e., the 'bad and ugly'), chromium and its stable isotopes $\left({ }^{53} \mathrm{Cr} /{ }^{52} \mathrm{Cr}\right.$ ratios) can be also 'good' especially when used as a sensitive and valuable tracer for the reconstruction of paleo-redox conditions of earth's surface environments over geological time, with implications for the oxygenation history of the ocean-atmosphere system and the evolution of life on our planet.

This contribution will present recent results from selected case studies from 'deep time' geological records of Australia, specifically Neoarchean and Proterozoic sedimentary rock records of intra-cratonic basins, where stable chromium isotopes $\left(\delta^{53 / 52} \mathrm{Cr}\right)$ have been used as a proxy to infer past redox conditions in both marine and terrestrial environments. These new results from the Pilbara region in Western Australia (Neoarchean Fortescue Group) and the Greater McArthur Basin in Northern Territory (Proterozoic records of the Beetaloo and Birrindudu Sub-basins) provide a unique 'window' into past redox conditions on the early Earth, spanning approximately 1.5 billion years $(\mathrm{Ga})$ of geological history (from $\sim 2.75 \mathrm{Ga}$ to $\sim 1.30$ $\mathrm{Ga}$ ). These Australian based 'deep time' chromium isotope records will be discussed in the context of other published $\mathrm{Cr}$ isotope datasets from Archean and Proterozoic sedimentary rock archives worldwide, with implications for paleo-redox conditions on the early Earth and the effects of secondary diagenetic processes on the $\mathrm{Cr}$ isotope proxy. Overall, this contribution will showcase and summarise recent applications of $\mathrm{Cr}$ isotopes for studies of Precambrian sedimentary archives, illustrating the potential and limitations of $\delta^{53 / 52} \mathrm{Cr}$ proxy as paleo-redox tracer for earth system evolution and problems relevant to fluid-rock interaction and diagenesis in sedimentary basins. 